\title{
Cyclin dependent kinase 5 and its interacting proteins in cell death induced in vivo by cyclophosphamide in developing mouse embryos
}

\author{
Y Zhu ${ }^{1,4}$, L Lin ${ }^{1,4}$, S Kim ${ }^{1}$, D Quaglino ${ }^{2}$, RA Lockshin ${ }^{3}$ and \\ Z Zakeri ${ }^{\star, 1}$ \\ ${ }^{1}$ Department of Biology, Queens College and Graduate Center of City University \\ of New York, Flushing, New York, NY 11367, USA \\ 2 Dipartimento Di Scienze Biomediche-Patologia Generale, Univ. di Modena e \\ Reggio Emilia, 41100 Modena, Italy \\ 3 Department of Biological Sciences, St. Johns University, Jamaica, New York, \\ NY 11439, USA \\ 4 Both authors contributed equally \\ * Corresponding author: Z Zakeri, Dept. of Biology, Queens College and \\ Graduate Center of City University of New York, Flushing, NY 11367, USA. \\ Tel: +1 718997 3417; Fax: +1 718997 3429; E-mail: Zahra_Zakeri@qc.edu
}

Received 7.3.01; revised 28.9.01; accepted 01.10.01

Edited by M Piacentini

\begin{abstract}
Activation or inactivation of members of the cyclin-dependent kinase family is important during cell cycle progression. However, Cdk5, a member of this family that was originally identified because of its high structural homology to Cdc2, is activated during cell differentiation and cell death but not during cell cycle progression. We previously demonstrated a correlation between the up-regulation of Cdk5 protein and kinase activity and cell death during development and pathogenesis. We report here that cyclophosphamide (CP) induces massive apoptotic cell death in mouse embryos and that Cdk5 is expressed in apoptotic cells displaying fragmented DNA. During CP-induced cell death, Cdk5 protein expression is substantially increased as detected by immunohistochemistry but not by Western blot, while its mRNA level remains the same as control, and its kinase activity is markedly elevated. The up-regulation of $\mathrm{Cdk} 5 \mathrm{during}$ $\mathrm{CP}$-induced cell death is not due to de novo protein synthesis. We also examined $\mathrm{p35}$, a regulatory protein of Cdk5 in neuronal differentiation. Using a yeast two-hybrid system, we isolated p35, a neuronal differentiation specific protein, as a protein that interacts with Cdk5 in CP-treated embryos. P35 mRNA level does not change, but the protein expression of p25, a truncated form of $\mathrm{p} 35$, is elevated during cell death in vivo, as established here, as well as during cell death in vitro. Our results suggest a role for $\mathrm{Cdk5}$ and its regulatory proteins during CP induced cell death. These results further support the view that $\mathrm{Cdk} 5$ and its regulation may be key players in the execution of cell death regardless of how the cell dies, whether through biological mechanisms, disease states such as Alzheimer's disease, or induction by CP.

Cell Death and Differentiation (2002) 9, 421-430. DOI: 10.1038/ sj/cdd/440967.
\end{abstract}

Keywords: cell death; cell cycle genes; cyclophosphamide; apoptosis

Abbreviations: $\mathrm{CP}$, cyclophosphamide; Cdk, cyclin-dependent kinase; Cdk5, cyclin-dependent kinase 5; AD, Alzheimer's disease

\section{Introduction}

The cyclin-dependent kinase (Cdk) family of serine/threonine protein kinases is important in cell growth, differentiation and death. Cdk5, one member of this family, is expressed in the mammalian embryonic nervous system, in differentiating rather than proliferating cells. ${ }^{1,2}$ In embryonic tissues, Cdk5 mRNA and protein are widely distributed, with the highest levels detected in the brain and testis., ${ }^{3,4}$ However, Cdk5 kinase activity, as measured by phosphorylation of histone $\mathrm{H} 1$, is detected only in embryonic brain ${ }^{5}$ and differentiating muscle. ${ }^{4}$

Recently we showed that the upregulation of Cdk5 expression is not unique to differentiating cells and is found also in dying cells. ${ }^{6}$ The induction of Cdk5 protein coincides with irreversible commitment to death following oxidative stress. ${ }^{7}$ Cdk5 protein is also induced when dopaminergic substantia nigra neurons die during normal development or are killed by quinolinic acid. ${ }^{8}$ Cdk5 protein has been reported to accumulate in neuronal tangles of the brains of Alzheimer's patients. ${ }^{8,9}$ On a functional basis it is perhaps more important that the kinase activity of Cdk5 is upregulated in apoptosis in mouse embryonic and several adult tissues ${ }^{6,10,11}$ as well as human kidney cells upon induction of cell death. ${ }^{9}$ These findings suggest a novel role for Cdk5 during apoptosis of neurons and other cells. Here we show that its activation can be detected when cell death is induced in vivo.

Cdk5 associates with several regulatory factors: several neuron-specific regulatory proteins, including p25, 9,11-13 $\mathrm{p} 35,{ }^{5} \mathrm{p} 39,{ }^{14}$ and Munc-18. ${ }^{15,16}$ Cdk5 kinase activity correlates with the expression of p35 rather than the expression of Cdk5 in the developing brain, ${ }^{17}$ and lack of p35 leads to cortical lamination defects. ${ }^{18}$ p35 may be truncated to p25, the C-terminal fragment, by calpain protease. Both p25 and p35 correlate with the expression of Cdk5 in developmental cell death, ${ }^{6}$ and induced cell death in COS-7 cells. ${ }^{11}$

In cultured neuronal cells p25 complexes with Cdk5 to form tau protein kinase II, which phosphorylates tau protein, destabilizes the cytoskeleton and leads to death. 1,11,12,19,20 p25 also accumulates in the brains of patients with Alzheimer's disease. ${ }^{9}$ Since Cdk5 binds to tau and tau anchors Cdk5 to microtubules, ${ }^{21}$ Patrick et al. ${ }^{9}$ suggested that translocation of the complex from cell membrane to cell 
soma in neurons leads to phosphorylation of tau, destabilization of the cytoskeleton, and the death of the neuron. Thus Cdk5 and p25 appear to correlate with cell death in cultured cells, and there is some evidence that this might be the case in situations of cell death in vivo. A better test of its role in vivo is to induce cell death in a living animal and observe the response.

Cyclophosphamide (CP), an alkylating agent that is commonly used in the treatment of cancer and progressive autoimmune disease, induces apoptosis. ${ }^{10,22-28}$ It is therefore also frequently used as an experimental teratogen. ${ }^{29}$ Here we use CP to induce cell death, and we document that Cdk5 protein and kinase activity are upregulated in embryonic tissues in a provoked cell death following induction by CP. We further illustrate that this upregulation is not transcriptional, as Cdk5 mRNA is not upregulated. Since p25/p35 is considered to be neuron-specific, we also ask whether death induced by CP would yield coordinated activation of Cdk5, p35, and p25 in a manner similar to that seen in neuronal cell death. With the use of the yeast twohybrid system we isolated the p35 regulatory protein during $\mathrm{CP}$ induced cell death. The expressions of this regulatory protein and of p25 correlate with the expression of Cdk5 during CP-induced cell death in non-neuronal cells as well as neurons, indicating that p25/p35 is not neuron-specific. Our findings confirm the roles for Cdk5 and p25/p35 in cell death and imply that Cdk5 acts in a common path during the progression of cell death regardless of how the cells are induced to die.

\section{Results}

\section{Cell death caused by $\mathrm{CP}$ is apoptotic}

To study the involvement of Cdk5 in CP induced cell death during mouse embryonic development, we asked if the induced cell death was regulated or controlled (i.e., apoptotic). We first evaluated the extent of cell death in the treated embryos by light and electron microscopy. We saw a massive increase in the number of dying cells in the treated embryos (Figure 1B) compared to the control (Figure 1A). The extensive cell death led to disorganization of the cellular pattern in different tissues (Figure 1B). The number of dead cells increased throughout the embryo and was not confined to specific cell types or organs. Electron microscopy indicated a regulated (apoptotic) type of cell death as depicted by typical condensed nuclei and some apoptotic cell fragments engulfed by phagocytic cells, although there were many more individual apoptotic than engulfed cells (Figure 1C). There are also occasional necrotic cells as well (Figure 1G). The low number of phagocytic cells was confirmed by immunohistochemistry (Figure 1D). We used an antibody targeting the mature macrophage cell surface marker F4/80, which is expressed on the surface of mature phagocytic cells in the developing embryo. ${ }^{10,25}$ Although there were a number of positively stained phagocytic cells with apoptotic cell fragments in them (Figure 1D), their number was fewer than the number of dead or dying cells that appeared apoptotic by morphologic criteria as well as by in situ TUNEL DNA fragmentation assay (Figure 1E). Lysosomal activity repre-

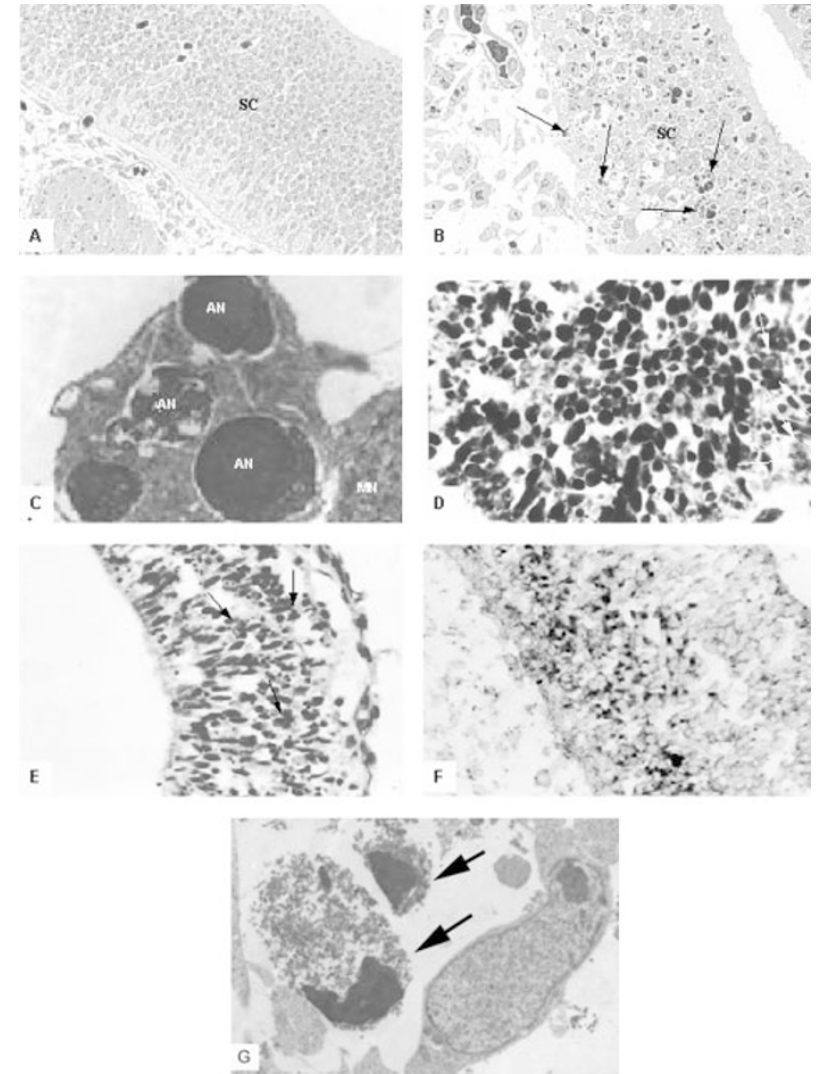

Figure $1 \mathrm{CP}$-induced cell death in mouse embryos is apoptotic. Pregnant female mice were injected with $\mathrm{CP}$ at gestation day 9.5, and embryos were removed $24 \mathrm{~h}$ later as described in Materials and Methods. Control mice were treated with saline only. Near serial sections were prepared from both control and $\mathrm{CP}$ embryos. Tissues were processed appropriately for the different evaluations. (A, B) Morphological examination of both control $(\mathbf{A})$ and $\mathrm{CP}(\mathbf{B})$ embryos. CP causes an abnormal morphology in spinal cord (SC), and results in a dramatic increase in cell death in SC (B, arrows indicate dead cells). (C) Electron microscopic images of cells for a section of the regions shown in (B) in CP-treated embryos, exhibiting cells with apoptotic nuclei (AN) and cells engulfed by phagocytes (MN for macrophagic nuclei). (D) Detection of macrophages (white arrows) using F4/80 antibody. (E) DNA fragmentation (TUNEL) shows many cells with fragmented DNA (black arrows) in CP embryos. (F) Acid phosphatase activity is indicated by the red staining in $\mathrm{CP}$ embryos. Original magnifications: A and B: $100 \times$; D: $400 \times$; E: $400 \times$; F: $100 \times$. A-F are spinal cord regions. (G) Necrotic cells (arrows) amid a field of normal cells. Although these cells have lysed in a necrotic manner, their chromatin is frequently condensed, suggesting that they began a sequence of apoptosis

senting cellular destruction also increased in areas with high concentrations of dead cells (Figure 1F). However, this increased activity was not limited to the phagocytic cells, implying a phagocyte-independent cell autonomous destruction of the dead cells (autophagic or type II cell death).

\section{Cdk5 is expressed in CP induced cell death}

The association of $\mathrm{Cdk} 5$ protein with developmental cell death is unique among members of the Cdk family. ${ }^{30}$ We asked if expression of Cdk5 protein correlated also with cell death induced by CP. We stained near serial sections of CP-treated embryos for Cdk5 protein expression. We detected high 

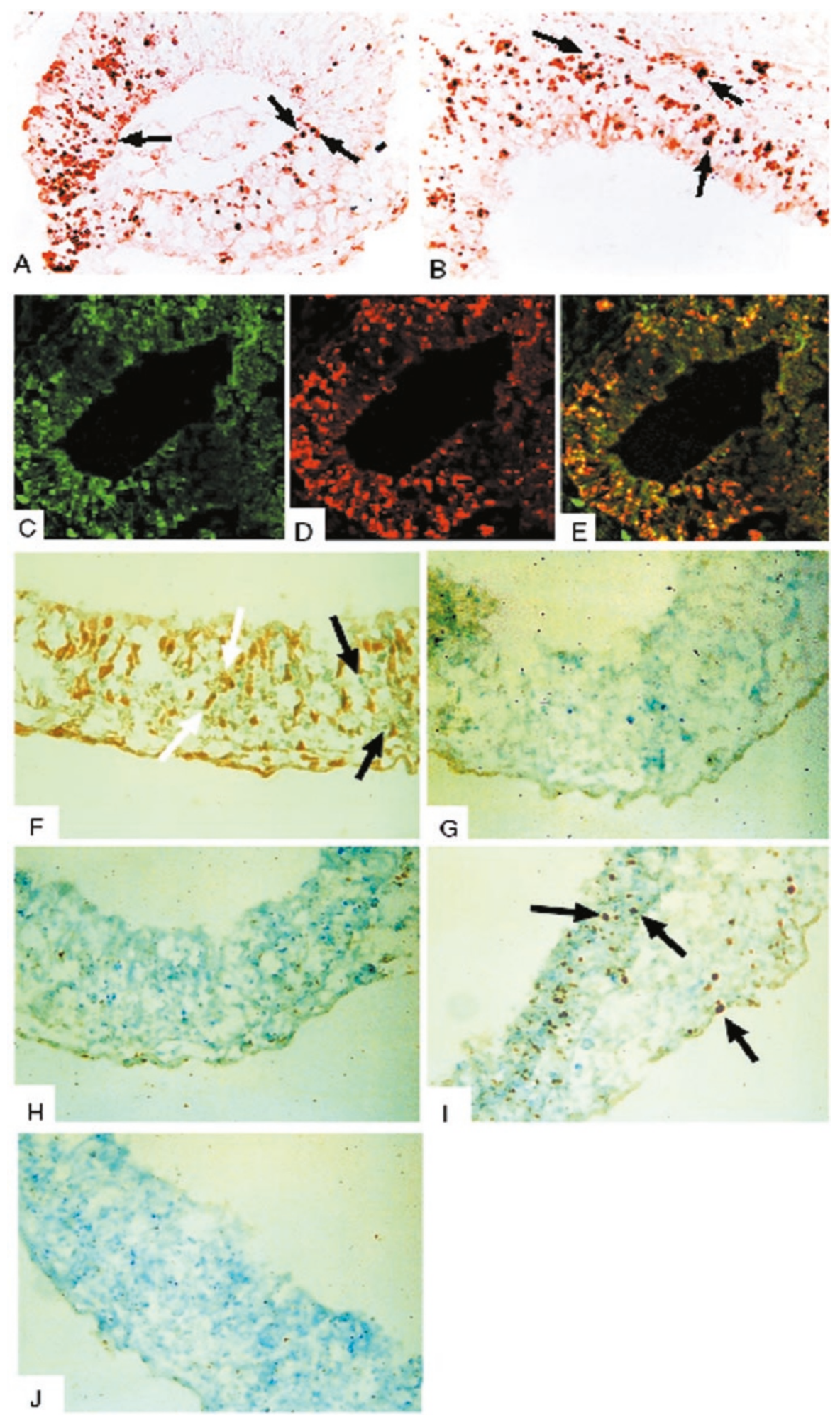

Figure 2 Cdk5 up-regulation is associated with cell death induced in CP-treated embryos. The preparation was as in Figure 1. (A, B, F- J) Slides were exposed to different Cdk antibodies, Cdk5 (A, B, I), Cdk2 (F), Cdk3 (G), Cdk4 (H), Cdk6 (J). While there are many cells labeled by Cdk5 antibody, as indicated by the arrows in (A), (B), and (I), there is no labeling by Cdk3, 4 and 6 antibodies (G, H, and $\mathbf{J})$. Although Cdk2 antibody labeled some cells $(\mathbf{F})$, this label is confined to proliferating cells (white arrows) and not dying cells (black arrows). (C-E) The association of Cdk5 expression and cell death is confirmed by double labeling immunohistochemistry in CP embryos. Slides were used to identify cell death by examining the cells with fragmented DNA alone (C); the expression of Cdk5 using cy3-conjugated secondary antibody (D); and both DNA fragmentation and Cdk5 by combining the two (E). The confocal overlaid image $(E)$ shows intense yellow staining where the two signals overlap. (A) and $(\mathbf{C}-\mathbf{E})$ show epithelia of the eye, (B) and $(\mathbf{F}-\mathbf{J})$ show neural epithelia. A, C-E: $100 \times ; \mathbf{B}, \mathbf{F}-\mathbf{J}: 400 \times$ 
expression of Cdk5 protein in treated embryos in areas of abundant cell death (Figure 2A,B). Cdk5 protein was localized in the cytoplasm of dying cells and was found both in individual dying cells and in cell fragments within phagocytic cells (data not shown), suggesting that its expression is relatively stable. To more precisely correlate the expression of Cdk5 protein with specific cells undergoing apoptosis, we used a double fluorescence labeling technique and confocal microscopy for in situ DNA fragmentation (FITC, green: Figure 2C) and Cdk5 protein (cy3, red: Figure 2D). To calculate the level of crossover between the FITC and cy3 detectors, we used separate near serial sections for single labeling to establish background levels. Using double labeling, we found an overlap between the expression of Cdk5 and DNA fragmentation in cells, as indicated by the intense yellow fluorescence (Figure 2E). This pattern of staining (yellow) indicated that Cdk5 was strongly detected in dying cells of $\mathrm{CP}$ treated embryos, as it is in dying cells of the interdigital regions of developing embryos. ${ }^{30}$

We assayed several members of the Cdk family by immunohistochemistry. In accordance with their eponymous designation as cell cycle-related proteins, none of the other Cdk proteins showed any correlation with cell death (Figure $2 \mathrm{~F}-\mathrm{H}, \mathrm{J})$. Although Cdk2 was expressed in $\mathrm{CP}$ treated embryos the expression was confined to the proliferating cells (Figure 2F) and was seen in control embryos as well (data not shown). Thus the association of Cdk5 with cell death was unique in CP-treated embryos (Figure 2l).

\section{Activation of Cdk5 kinase correlates with increased detection of Cdk5 protein in dying cells}

We next asked if the increased detection of Cdk5 reflected an upregulation of its message. For this analysis we used both Northern blotting and in situ hybridization. We found no difference in message level between control and treated embryos by Northern analysis (Figure $3 \mathrm{~A}$ ). This result was confirmed by in situ hybridization where we found mRNA expression in both control and CP treated day 10.5 embryos, with no change in the level of the message in the CP embryos as compared with control (Figure 3B). This result correlates with our earlier findings during normal development, ${ }^{30}$ and
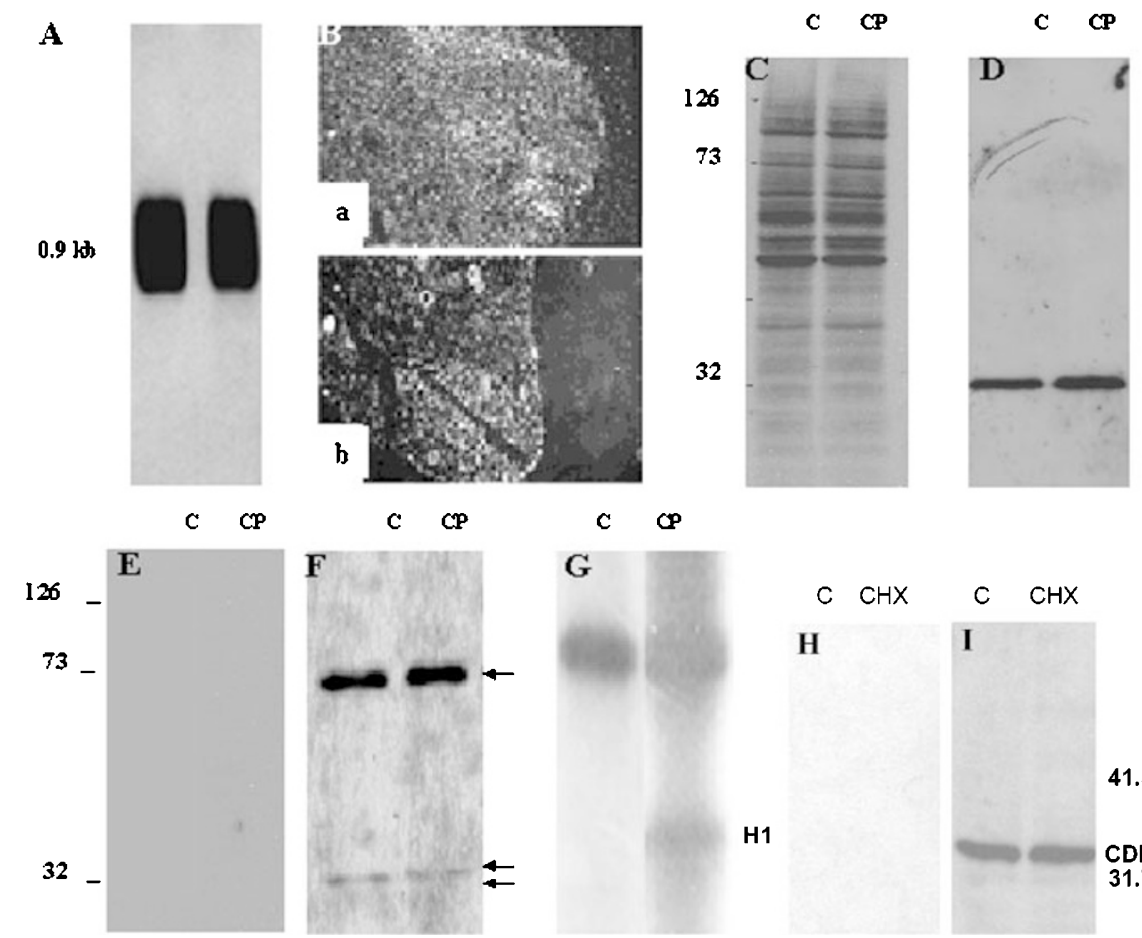

C $\quad C P$
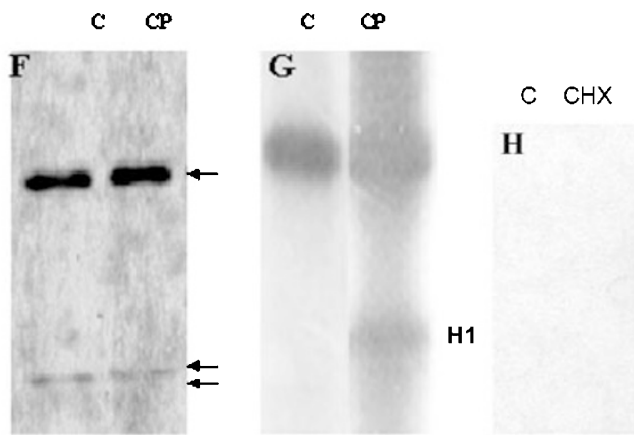

C $\mathrm{CHX}$

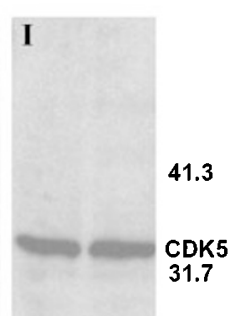

Figure 3 CP treatment causes no change in Cdk5 mRNA level, a slight change in protein level, and a dramatic increase in kinase activity. Furthermore, the upregulation of Cdk5 in CP-treated embryos is not due to de novo Cdk5 protein synthesis. Northern blot, in situ hybridization, ${ }^{35} \mathrm{~S}$-methionine labeling and Western blot are described in Methods and Materials. (A) Northern blot probed with ${ }^{32}$ P-labeled Cdk5 RNA probe demonstrates an equal amount of Cdk5 mRNA in control (left) and CP (right) embryos. (B) In situ hybridization of antisense to Cdk5 mRNA in control (a) and CP (b) embryos, $100 \times$. (C) Autoradiograph of total ${ }^{35} \mathrm{~S}$ methionine incorporation. Equal amounts of lysates from control and CP embryos were run on SDS-PAGE and blotted onto nitrocellulose membrane. The membrane was exposed to a film, indicating that the radioactivity was incorporated into many different proteins in both control and CP embryos. (D) Immunoblot of equal amounts of lysates of control (left) and CP (right) embryos, exposed to Cdk5 antibody. By densitometry, there was no change in CP embryos. (E) shows the results of $\mathrm{Cdk} 5$ immunoprecipitated labeled proteins. Equal amounts of ${ }^{35} \mathrm{~S}$-methionine labeled lysates from control and $\mathrm{CP}$ embryos were incubated with $\mathrm{Cdk5}$ antibody for $1 \mathrm{~h}$, and the precipitates were run on SDS-PAGE and autoradiographed. The gels showed no radioactive signal, therefore no Cdk5 synthesis. (F) The same precipitates as in (E) were blotted to membrane and exposed to anti-Cdk5 antibody for Western blotting to show Cdk5 expression. The upper band (single arrow) is IgG. Cdk5 (double arrows) level is unchanged. (G) Histone $\mathrm{H} 1$ kinase activity in immunoprecipitates of Cdk5 from control and CP embryos. The kinase activity rises substantially from undetectable levels. In the above experiments, $12.5 \%$ acrylamide gel was used. (H) Immunoblot of equal amounts of ${ }^{35} \mathrm{~S}$ methionine-labeled control (c) and $\mathrm{CHX}$-treated (CHX) Cos-7 cells immunoprecipitated using Cdk5 antibody and preparation as in (E). (I) Aliquots of samples used in $(\mathbf{H})$ were used for Western blotting using anti-Cdk5 antibody. A strong signal for Cdk5 protein was detected in both control and treated cells 
suggests that $\mathrm{Cdk} 5$ message is not upregulated during $\mathrm{CP}$ induced cell death.

The high signal for Cdk5 protein detected by immunohistochemistry in dead cells of CP treated embryos (Figure $2 A, B, I)$ does not correspond to the statistically insignificant changes (as determined by densitometry of 10 blots) in the amount of Cdk5 protein by Western blot (Figure 3D). We further confirmed that there was no synthesis of Cdk5. We treated the embryos with $\mathrm{CP}$ and labeled synthesized protein in vitro with ${ }^{35} \mathrm{~S}$-methionine. Although many proteins were labeled (Figure $3 \mathrm{C}$ ), we did not detect any de novo synthesis of Cdk5 as indicated on the autoradiograph of labeled Cdk5 protein following immunoprecipitation (Figure $3 \mathrm{E})$. Western blots after immunoprecipitation of ${ }^{35} \mathrm{~S}$-labeled control and CP-treated embryos using Cdk5 antibody showed the presence of the relatively stable Cdk5 protein (Figure 3F). We find similarly, using Cos-7 cells, that although there is an incorporation of ${ }^{35} \mathrm{~S}$-methionine in both control cells and those treated with cycloheximide, we detect no synthesis of Cdk5 after pulldown using Cdk5 specific antibody and immunoprecipitation (Figure $3 \mathrm{H}$ ). However, when the same blot is probed with Cdk5 antibody we see ample amounts of endogenous Cdk5 protein (Figure 3l). This finding suggests that regulation of Cdk5 may not be translational. It is likely to be post-translational modification although with this experiment we cannot rule out alteration in stability although this is unlikely since this should be reflected by Western blot as well. The abundant Cdk5 protein detected by immunohistochemistry could reflect a structural rearrangement that enables better antibody recognition in this situation. This can be due to a modification of the protein such as phosphorylation, which could also alter the localization of the protein within the cell. Another possibility is that in the embryo the number of dying cells represents only a small percentage of the total cells, so that an increase of Cdk5 in individual cells, easily detectable by immunohistochemistry, is not detectable by immunoblot against the background of normal cells. However, we likewise get no increase by incorporation of isotope or by immunoblot when we expose

\section{A. DNA sequence Analysis}

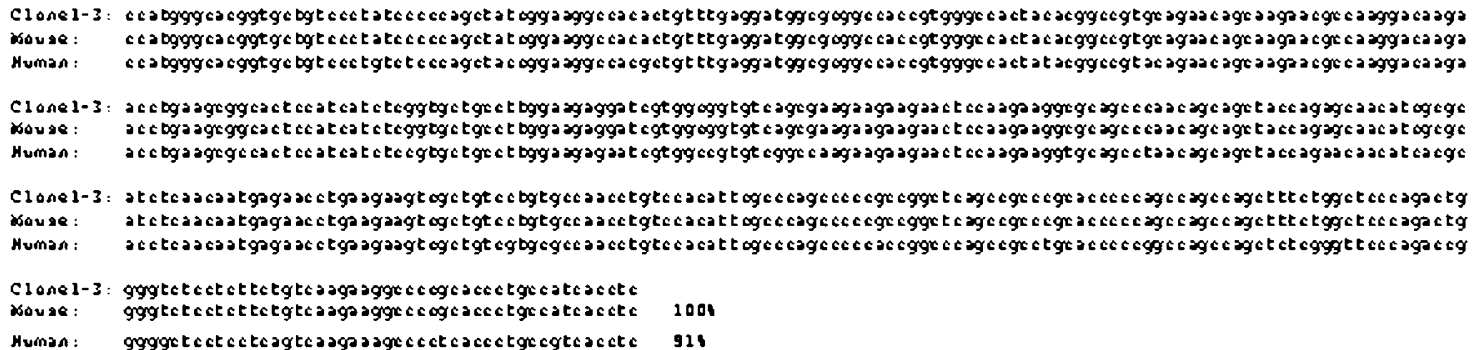

B. Protein Sequence Analysis

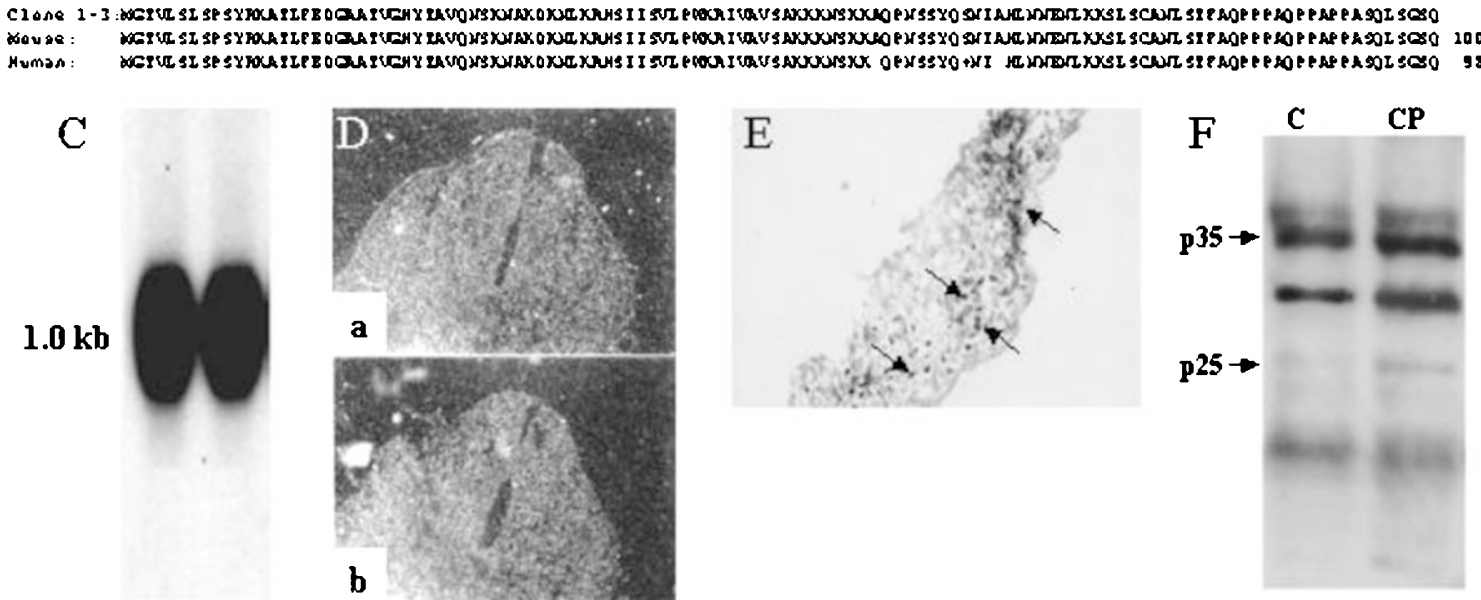

Figure 4 p35 interacts with Cdk5 in CP-treated mouse embryos. Via yeast two-hybrid system, we found p35 to interact with Cdk5 from cDNA library of CP embryos. (A) DNA sequence analysis of the clone 1-3. The upper line is DNA sequence of clone 1-3; lower line is human p35 DNA sequence. The homology between the two sequences is $91 \%$. The middle line is the mouse sequence. (B) Amino acid sequence analysis of the clone $1-3$. The upper line is amino acid sequence of clone 1-3; lower line is human p35 protein sequence. The homology between the two sequences is $98 \%$. The middle line is the mouse sequence, which like the DNA sequence shows $100 \%$ homology to clone 1-3. (C) Northern blot of equal amounts of total RNAs of control (left) and CP (right) embryos, probed with ${ }^{32} \mathrm{P}$-labeled p35 RNA probe. (D) In situ hybridization of antisense probe to p35 mRNA in different areas of sections of control (a) and CP (b) embryos, $100 \times$. (E) Immunohistochemical staining of p35 on sections of CP embryos, indicating some positively labeled cells (arrows), $400 \times$. (F) Immunoblot of equal amounts of lysates of control (left) and CP (right) embryos, exposed to p35 antibody. There is no measurable change in the level of p35 mRNA as measured either by Northern blot $(\mathbf{C})$ or in situ hybridization (D). In 10 runs of Western blots, CP caused a consistent but very slight increase in the p35 band, together with a substantial (approximately 3 -fold) increase in the truncation product p25 (F) 
Cos-7 cells to $\mathrm{CHX}$ (Figure $3 \mathrm{H}, \mathrm{I})$. In this instance $40-50 \%$ of the cells are killed within $24 \mathrm{~h}$, suggesting that we should have been able to detect a specific synthesis of Cdk5 protein.

To address the possibility of post-translational modification, we examined the kinase activity of Cdk5 in both control and treated embryos. Cdk5 kinase activity was assessed in an in vitro assay using histone $\mathrm{H} 1$ as a substrate. We found little or no activity in the control embryos (Figure 3G, left lane). However, the CP treated embryos showed substantial kinase activity (Figure 3G, right lane). The detection of the kinase activity is indicative of activation of $\mathrm{Cdk} 5$ during cell death and therefore indicates a role for Cdk5 activity in CP induced death.

\section{Isolation and expression of p35 and its truncation fragment p25 during cell death in CP treated embryo}

The kinase activity of $\mathrm{Cdk} 5$ is dependent on its interaction with regulatory proteins such as p35, p23, p39, etc. ${ }^{12-17}$ To identify proteins interacting with Cdk5 during cell death we used a yeast two-hybrid system and isolated several positive clones using mRNA isolated from CP treated embryos and full length human Cdk5 as bait. After co-transforming bait and cDNA library into yeast wild-type strain, all cells were cultured on selective medium plates. We used $\beta$-galactosidase assays to identify positive colonies for further study by sequencing. One colony (clone 1-3) showed 98\% homology (Figure 4A) at protein and $91 \%$ (Figure 4B) at DNA level to human p35, and $100 \%$ homology at both levels to mouse p35 (Figure $4 A, B)$. This result strongly suggested that $p 35$ was associated with Cdk5 in CP-treated embryos.

Having detected the interaction of Cdk5 and p35 in CP treated embryos by the yeast two-hybrid system, we asked if we could detect this association specifically in dying cells. As was the case with Cdk5, we saw no upregulation of p35 mRNA either by northern (Figure 4C) or by in situ analysis (Figure 4D). Although by Western blot we found only a very small but consistent increase in p35 protein in the CP treated embryos (Figure 4F), immunohistochemical analysis showed a high signal for p35 protein in the dying cells of $\mathrm{CP}$ treated animals when antibody to the $\mathrm{C}$ terminal region of p35 protein was used (Figure 4E). Antibody to the $\mathrm{N}$ terminal region did not detect any signal in dying cells (data not shown), suggesting specificity to the $C$ terminal region. Furthermore, using the C-terminal specific antibody we detected by Western blot the appearance of a $25 \mathrm{kD}$ protein in CP treated embryos (Figure 4F). The amount of the $25 \mathrm{kD}$ protein is small relative to the amount of p35, presumably reflecting the limited number of cells expressing it (Figure 4E). These results together suggest that the Cdk5 interacting protein in this type of cell death is most likely p25, which can be detected only using the antibody corresponding to the C-terminus of p35. As is the case with Cdk5, the immunoblot is much less sensitive a measure than the immunohistochemistry. These experiments for the first time show a direct correlation between the appearance of p25 and Cdk5 in dying cells in an in vivo induced cell death.

\section{Discussion}

Cdk5 is associated with cell death, most likely at the kinase activity level, in CP treated embryos

In this study, we compared the expression patterns of cyclin dependent kinases and cell death induced by $\mathrm{CP}$ in the developing embryo. The results show that of all the kinases examined, only Cdk5 is associated with apoptosis. Although it is difficult to assess the kinetics of death, since apoptosis is not synchronous in this in vivo system, we can approximate it using the appearance of dying cells and their engulfment by phagocytic cells. Cdk5 is expressed in cells that retain good nuclear morphology with intact cytoplasm representing an early stage of cell death. We also detect Cdk5 in the engulfed fragments of cells within phagocytic cells at late stages of cell death. We conclude that the activation of Cdk5 is an early and stable event during cell death. There is evidence that accumulated p25 in the brains of AD patients may cause mislocalization of Cdk5 in affected neurons, due to the different distribution of p35 (abundant in membrane) and p25 (enriched in cytosol) as seen in in vivo neuronal cultures. ${ }^{9}$ In our system, as for AD patients, it is very difficult to assess the cellular localization. However, most of the labeling we detected for both proteins was clearly in the cytoplasm and not confined to a specific region of the cytoplasm.

In freshly excised tissue, the total Cdk5 protein is slightly higher, and Cdk5-associated kinase activity in the CP treated embryo is much higher, than in the control. In the fresh tissue preparations Northern blots detect no differential expression of mRNA in dying cells, although the preparations were as healthy as could be expected and we achieved reasonable labeling of proteins. This strongly suggests that the transcription of Cdk5 is not regulated in the dying cell. mRNA transport out of the nucleus was not measured by the methods used, but in situ hybridization did not indicate any obvious differences in the level of Cdk5 mRNA between the nucleus and the cytoplasm. Our results concerning the effect on translation also argue that there is no stabilization of the message or marked increase in the level of Cdk5 protein synthesis due to cell death.

We find a much higher kinase activity and stronger detection of protein by immunohistochemical evaluation in the treated embryo, which is less reflected by Western blot measurements of Cdk5 protein. We interpret this result to indicate that during cell death the total amount of protein may not increase massively; the strong increase detected by immunohistochemistry may reflect a modification of the protein, perhaps phosphorylation leading to a change in compartmentalization, allowing better detection by the antibody, or other molecular or physiological changes. We are evaluating the details of how this happens. However, our findings strongly suggest that the role of Cdk5 in cell death is linked to its activity and not accumulation.

\section{The interaction between Cdk5 and p35, p25 in CP-induced cell death}

The interaction of p35 with Cdk5 has been shown during differentiation. Here we demonstrate the interaction of p35 with Cdk5 in CP-induced cell death. We have also 
demonstrated the appearance and interaction with Cdk5 of p25 protein in CP-treated embryos similar to that seen in neural cell death. The appearance and induction of p25 in our system correlates with the induction of kinase activity of the Cdk5 protein. This argument is supported by the findings that p25, corresponding to the C-terminal region of p35, is the activator of Cdk5 during cell death in neuronal cultures after serum withdrawal, or the cell death that occurs when both p35 and Cdk5 are overexpressed in COS-7 cells. ${ }^{6,11}$ In these preparations also, triggering of apoptosis by cycloheximide or camptothecin did not lead to synthesis of Cdk5 protein, even though we detected increases by immunohistochemistry and by measurement of kinase activity (Zhu and Zakeri, in preparation).

\section{The possible functions of Cdk5 in cell death}

The role of Cdk5 is clear neither in cell differentiation nor in cell death. Although the introduction of p25 appears to be the key in the activity of Cdk5 in cell death, embryonic development appears to be normal. No specific problems with Cdk5 regulation are reported for p53 knockout mice, and there are also no reported defects in cell death. Initial embryonic development of both Cdk5 and p35 knockout mice appears to be normal. However, adult mice lacking p35 display severe cortical lamination defects and suffer sporadic adult lethality and seizure. ${ }^{18}$ Cdk5-/- mice display late embryonic and perinatal lethality, with an abnormal stratification of cortical neurons as well as those in the hippocampus. They also lack foliation and layering in the cerebellum. ${ }^{31}$ The more severe abnormality of Cdk5-/- mice compared to p35-/- mice likely reflects the existence of other Cdk5 regulatory proteins. Cell death is normal in early Cdk5-/- embryos, indicating either that Cdk5 may modify the mode of death but does not actually control it, or that there is more redundancy of function for Cdk5 in cell death than for neuronal differentiation.

Cdk5/p35 kinase activity is required for neurite outgrowth and cortical lamination, but the function of the kinase during neuronal differentiation is not clear. Kwon et al. ${ }^{32}$ suggested that Cdk5 and p35 regulate neuronal migration in the developing cortex by changing the association between $\beta$-catenin (which binds with p35) and N-cadherin. Cdk5 also phosphorylates neurofilament proteins, directing them to axons, where they affect axonal transport and conduction velocity. ${ }^{31,33}$ The microtubule-associated tau protein is the main substrate of Cdk5 kinase in pathogenesis of Alzheimer's disease. ${ }^{34}$ In other systems, collapse of the cytoskeleton is an early event in cell death. ${ }^{35,36}$ Our results indicate that Cdk5 is very stable and its activation is most likely early, before many of the cytological alterations. This is consistent with the suggestion that Cdk5 initiates disruption of cytoskeletal components. We are now correlating the activation of Cdk5 with this and other known events during cell death.

How CP induces cell death is not known. The fact that Cdk5 is activated in CP induced cell death argues that CP induced cell death is similar to developmentally induced and other types of cell death. We see the classical features of apoptosis, but much less phagocytosis of the dead cells. This cannot be simply explained by the fact that many cells die or that death is too rapid for infiltration of phagocytic cells or the differentiation of the neighboring cells to do the job since after treatment with retinoic acid, for example, we find massive selective cell killing as well as high levels of phagocytic cells in the affected area. ${ }^{10}$ Thus CP-induced death may extend to types of cell death that are not completely apoptotic and may be autophagic, as is suggested by the activation of lysosomes (Figure 1F). We are currently exploring the activation of Cdk5 in autophagic and necrotic types of death. Minimally, it is clear that Cdk5 activation is not necessarily followed by infiltration of phagocytes, and the activation could therefore be upstream or entirely independent of phagocytes.

The activation and regulation of Cdk5 in cell death generated from multiple situations, i.e., in Alzheimer brain and $\mathrm{CP}$ induced cell death argues for an existence of a common, perhaps functional, step in these differently induced cell deaths. We can therefore use Cdk5 activation as a tool to evaluate upstream and downstream steps in the progression of these types of cell death.

\section{Materials and Methods}

\section{Embryo and CP treatment}

Swiss Webster mice (Charles River Laboratories, Wilmington, MA, USA) were mated overnight, and females were checked for vaginal plugs. Positive females were designated as gestational day 0.5 . On gestational day 9.5 females were injected intraperitoneally with $10 \mathrm{mg} /$ $\mathrm{kg}$ body weight of CP (Sigma, St. Louis, MO, USA) dissolved in $0.9 \%$ saline. ${ }^{37}$ The treated mice were sacrificed by cervical dislocation $24 \mathrm{~h}$ after injection, and the embryos were removed.

\section{Tissue preparation and microscopy}

Embryos were washed with PBS (phosphate-buffered saline, $145.4 \mathrm{mM} \mathrm{NaCl}, 2.68 \mathrm{mM} \mathrm{KCl}, 10 \mathrm{mM} \mathrm{Na}_{2} \mathrm{HPO}_{4}, 1.8 \mathrm{mM} \mathrm{KH}_{2} \mathrm{PO}_{4}$, $\mathrm{pH}$ 7.4). For morphological examination the embryos were fixed in $2.5 \%$ glutaraldehyde (Fluka Ag, Buchs/Switzerland) in PBS (pH 7.4) for $24 \mathrm{~h}$, washed in PBS twice, and dehydrated in the sequence of 50 , 75,90 , and $100 \%$ ethanol. For ultrastructural analysis, the whole embryo was fixed in $2.5 \%$ glutaraldehyde in PBS ( $\mathrm{pH} 7.2$ ). Specimens were then dehydrated in ethanol and propylene oxide and embedded in Spurr (Agar Scientific Lt., Stansted, UK). Embryos were carefully oriented in order to obtain sagittal or frontal sections. Semi-thin sections stained with toluidine blue were observed with a Zeiss light microscope, and ultrathin sections were stained with uranyl acetate and lead citrate and observations were performed using a JEOL 1200 electron microscope. For cytochemistry the embryos were fixed in $4 \%$ paraformaldehyde with shaking at $4^{\circ} \mathrm{C}$ for $18-24 \mathrm{~h}$, and partially dehydrated in $20 \%$ sucrose solution in PBS overnight. Embryos were then embedded in OCT compound (Miles, Elkhart, IN, USA) for sectioning at $5 \mu \mathrm{m}$.

\section{Detection of lysosomal activity}

To measure lysosomal activity, acid phosphatase was analyzed as in Zakeri et al. ${ }^{38}$ using kits from Sigma (St. Louis, MO, USA). Briefly, tissue sections were postfixed with citrate ( $\mathrm{pH} 3.6)$, acetone and $37 \%$ formaldehyde (13:33:4 by volume) for $30 \mathrm{~s}$, and treated with naphthol 
AS-BI phosphate and fast garnet stain. The slides were washed and counterstained with methylene blue and mounted in Crystal Mount ${ }^{\mathrm{TM}}$ (Biomedia, Foster City, CA, USA).

\section{Detection of phagocytic cells}

For detection of phagocytic cells, sections were prepared and stained as reported in Zakeri et al. ${ }^{38}$ as well as in Zakeri and Ahuja. ${ }^{25}$ Sections were rehydrated, the endogenous peroxidase activity was abolished by treatment with hydrogen peroxide, and nonspecific binding sites were blocked with serum. Primary antibody F4/80 (Serotec, Raleigh, NC, USA), diluted at $1: 10$, was applied overnight at $4^{\circ} \mathrm{C}$. A $1: 50$ dilution of secondary antibody, peroxidase-labeled $F(a b)_{2}$ fragment of goat anti-rat IgG $(\mathrm{H}+\mathrm{L})$ (Jackson Immuno Research Laboratories, West Grove, PA, USA), was applied for $2 \mathrm{~h}$. Phagocytic cells were visualized by diaminobenzidine (DAB) solution (Research Genetics, Huntsville, AL, USA).

\section{Detection of DNA fragmentation}

Detection of DNA fragmentation was performed by using nonisotopic digoxigenin-11-dUTP and terminal transferase (ApopTag ${ }^{\mathbb{R}}$ kit, Intergen, Purchase, NY, USA) ${ }^{10,38}$ Briefly, sections were post-fixed with $\mathrm{EtOH}: \mathrm{HOAc}$, and endogenous peroxidase activity was quenched with $0.1 \%$ hydrogen peroxide. Sections were equilibrated with terminal deoxynucleotidyl transferase (TdT) buffer for $5 \mathrm{~min}$ and then incubated with TdT for $1 \mathrm{~h}$ at $37^{\circ} \mathrm{C}$. The digoxigenin-11-dUTP binding to the free end of the oligonucleotide was detected by anti-digoxigenin-Abperoxidase and DAB for visualization. The sections were counterstained with methyl green and mounted with Permount ${ }^{\mathbb{R}}$ (Fisher Scientific, Burr Ridge, IL, USA).

\section{Immunohistochemistry}

The avidin-biotinylated-peroxidase complex $(A B C$-Vectastain $A B C$ kit, Vector Laboratory, Burlingame, CA, USA) was used to detect in situ protein levels of Cdks and p35. ${ }^{6}$ Cdks and p35 antibodies were purchased from Santa Cruz Biotechnology (Santa Cruz, CA, USA). Cdk2, 3, 4, 5, 6 antibodies are Cdk2 (M2), Cdk3 (Y-20), Cdk4 (C-22), Cdk5 (C-8), and Cdk6 (C-21), respectively. Two types of p35 antibody has been used, $\mathrm{N}-20$ which targets the $\mathrm{N}$-terminal end of p35 protein, and C-19, which recognizes the C-terminus. Sections were twice washed in PBST (PBS with $0.1 \%$ Tween) and incubated in $100 \%$ methanol containing $0.3 \%$ peroxide for $20 \mathrm{~min}$ to abolish endogenous peroxidase activity. After washing with PBST, sections were incubated for $1 \mathrm{~h}$ in blocking solution, and overnight with primary antibody at a concentration of $0.2 \mu \mathrm{g} / \mathrm{ml}$ at $4^{\circ} \mathrm{C}$ in a humidified chamber. The sections were washed three times with PBST and incubated with secondary biotinylated antibody for $1 \mathrm{~h}$ at RT. After a wash with PBST, sections were incubated with $A B C$ reagent for $2 \mathrm{~h}$ at $\mathrm{RT}$ and rinsed three times. For visualization of immunostaining, slides were incubated with DAB solution for $2 \mathrm{~min}$, washed three times with distilled water, counterstained with methylene blue, and mounted.

\section{Immunohistochemistry and DNA fragmentation double labeling}

Fluorescence detection of DNA fragmentation and Cdk5 expression were used as in Ahuja et al. ${ }^{30}$ Briefly, sections were twice washed in PBS, postfixed in ethanol: acetic acid $(2: 1)$ for $5 \mathrm{~min}$ at $-20^{\circ} \mathrm{C}$, and again twice washed. Sections were placed for $5 \mathrm{~min}$ in equilibration buffer (Apoptag ${ }^{\mathbb{R}}$ kit, Intergen, Purchase, NY, USA), and the solution was changed for one containing TdT and the incubation was continued for $1 \mathrm{~h}$ at $37^{\circ} \mathrm{C}$. The slides were immersed in pre-warmed stop-wash buffer for $30 \mathrm{~min}$, rinsed three times with PBS, and exposed to antidigoxigenin FITC fluorescein and incubated for $30 \mathrm{~min}$. After a wash with PBST, slides were incubated for $20 \mathrm{~min}$ in $0.3 \% \mathrm{H}_{2} \mathrm{O}_{2}$, followed by two washes with PBST. Primary anti-Cdk5 antibody was added to blocking solution ( $1 \mathrm{mg} / \mathrm{ml}$ bovine serum albumin in PBST) to a final concentration of $1 \mu \mathrm{g} / \mathrm{ml}$. The incubation in primary antibody was overnight at $4^{\circ} \mathrm{C}$. The sections were washed three times with PBST, incubated with secondary biotinylated antibody overnight at RT, and again rinsed three times. Fluorescent signal was added by incubating the slides with cy3-conjugated IgG mouse anti-biotin (Jackson Immuno Research Laboratory, West Grove, PA, USA) for $30 \mathrm{~min}$. The slides were mounted with $90 \%$ glycerol and observed under an Ultima $312^{\mathrm{TM}}$ confocal microscope (Meridian International, Inc., Okemos, MI, USA). DNA fragmentation is seen with FITC as green and the Cdk5 as detected by cy3 is red.

\section{Western blot analysis}

Both control and $\mathrm{CP}$ treated embryos were homogenized in RIPA buffer (50 mM Tris, pH 7.5, $150 \mathrm{mM} \mathrm{NaCl}, 1 \%$ Triton 100X, 0.1\% SDS, $0.5 \%$ Sodium deoxycholate, $2 \mathrm{mM}$ EDTA, and protease inhibitor cocktail tablets (Boehringer Mannheim, Germany). The lysates were cleared by centrifugation, and Bradford ${ }^{39}$ assay was done to determine protein concentration. Equal amounts of protein were added with equal volume of $2 \times$ Laemmli loading buffer (100 mM Tris, $\mathrm{pH} 7.5,4 \%$ SDS, $20 \%$ glycerol, $0.002 \%$ bromophenol blue $)^{40}$ before they were run on $12.5 \%$ or $15 \%$ SDS-polyacrylamide gels. Gels were blotted onto nitrocellulose membranes and blocked overnight with $5 \%$ dry milk in PBST. Blots were incubated with primary antibody $(0.5 \mu \mathrm{g} /$ $\mathrm{ml} \mathrm{Cdk5}$ or p35) and placed on the shaker overnight at $4^{\circ} \mathrm{C}$. After three washes with PBST, blots were incubated with horseradish peroxidase (HRP) conjugated goat anti-rabbit antibody for $1 \mathrm{~h}$ followed by three washes. The immune complexes were detected by chemiluminescence (ECL kit, Amersham, Chicago, IL, USA) and exposed to autoradiographic film.

\section{In vitro histone $\mathrm{H} 1$ kinase assays}

Cdk5 kinase activity was assayed as described by Zhang et al. ${ }^{6}$ Equal amounts of lysates from control and CP embryos were incubated with $1.5 \mu \mathrm{g} / \mathrm{ml} \mathrm{Cdk5}$ antibody for $1 \mathrm{~h}$ at $4^{\circ} \mathrm{C}$, and then purified by the addition of protein A-Sepharose (Boehringer Mannheim, Germany). The precipitated beads were equilibrated in kinase buffer ( $50 \mathrm{mM}$ Tris, $\mathrm{pH} 7.5,10 \mathrm{mM} \mathrm{MgCl}$, $1 \mathrm{mM}$ DTT, $20 \mathrm{mM}$ EGTA, $0.1 \mathrm{mM}$ sodium vanadate, $80 \mathrm{mM} \beta$-glycerophosphate) and collected by centrifugation. Histone $\mathrm{H} 1$ kinase assays were performed in kinase buffer supplemented with $0.1 \mu \mathrm{Ci} / \mathrm{ml}\left[\gamma_{-}{ }^{32} \mathrm{P}\right] A T P(6000 \mathrm{Ci} / \mathrm{mM})$ (Amersham Pharmacia Biotech., Piscataway, NJ, USA), $10 \mathrm{mM} \mathrm{ATP,} 50 \mu \mathrm{g} / \mathrm{ml}$ calf thymus histone $\mathrm{H} 1$ (Boehringer Mannheim, Germany), and $5 \mu \mathrm{M}$ cAMP-dependent protein kinase inhibitor (Sigma, St. Louis, MO, USA) at $30^{\circ} \mathrm{C}$ for $30 \mathrm{~min}$. An equal volume of $2 \times$ Laemmli buffer was added to each sample before they were denatured at $100^{\circ} \mathrm{C}$ for $2 \mathrm{~min}$. Following electrophoresis, gels were fixed, dried, and exposed to film. The intensity of the bands was quantified using a Storm Imaging System (Molecular Dynamics Inc., Sunnyvale, CA, USA).

\section{${ }^{35} \mathrm{~S}$ methionine labeling}

ED10.5 embryos were removed from pregnant female mice and placed in DMEM (Dulbecco's Modified Eagle Medium, Life Technologies, Grand Island, NY, USA) culture medium supplemented with $30 \%$ FBS 
(fetal bovine serum, Life Technologies), $50 \mathrm{U} / \mathrm{ml}$ penicillin and $100 \mu \mathrm{g} /$ $\mathrm{ml}$ streptomycin (Life Technologies), and $100 \mu \mathrm{Ci} / \mathrm{ml}^{35} \mathrm{~S}$ methionine (Amersham Pharmacia Biotech., Piscataway, NY, USA), on a shaker, at $37^{\circ} \mathrm{C}$ with $5 \% \mathrm{CO}_{2}$, for $3 \mathrm{~h}$. Embryonic viability was ascertained by beating of the heart. During the $3 \mathrm{~h}$ incubation, we found all of the embryos to be viable. The embryos were washed with PBS several times before being lysed in RIPA buffer. The lysates of embryos were stored at $-20^{\circ} \mathrm{C}$ for both Western blot and immunoprecipitation.

\section{Construction of CP treated day 10.5 mouse embryo yeast two-hybrid CDNA library}

CP was injected intraperitoneally into pregnant ED9.5 mice at a dose of $10 \mathrm{mg} / \mathrm{kg}$ body weight. Twenty-four hours later, mice were sacrificed, and embryos were removed for mRNA isolation. Total RNA was extracted using guanidinum thiocyanate. Poly $(A)^{+}$RNAs were isolated using mRNA separator columns from Clontech Laboratories, Inc. (Palo Alto, CA, USA). cDNA libraries that contain GAL-4 transactivation domain vector pGAD10 were constructed by making use of a Clontech two-hybrid CDNA library construction kit. Poly $(\mathrm{A})^{+}$RNA was reverse transcribed, and then used as template to synthesize the second strand. This cDNA was ligated to the EcoRI adaptor and ligated into the vector pGAD10. This ligation mixture was transformed into $E$. coli $\mathrm{DH} 5 \alpha$ competent cells by electroporation. After plating, we calculated the titer of the library as over $1.3 \times 10^{9}$, confirming the maximum efficiency of the transformation.

\section{Interactive cloning using yeast two-hybrid system}

A full-length human Cdk5 cDNA (gift from Dr. Li-Hui Tsai, Harvard Univ.) was cloned as a Ndel-Smal fragment into the same site of the yeast GAL-4 fusion vector pAS2 (Clontech) such that a GAL-4 DNAbinding domain/Cdk5 fusion protein was encoded. pAS2 carries tryptophan selection. This plasmid was transformed into yeast $Y 190$ (Clontech). Cells were selected on media lacking tryptophan. Growing colonies were picked out and checked for $\mathrm{Cdk} 5$ expression activity by Western blot using Cdk5 antibody. The colony with the highest expression, named Y190-Cdk5, was used as host yeast strain. Five hundred micrograms of a GAL-4 transactivation domain/CP treated mouse day 10.5 embryo cDNA library in pGAD10 (which carries leucine selection) was transformed into Y190-Cdk5. Vigorously growing colonies were subjected to $\beta$-galactosidase assays and pGAD10 plasmids rescued by transformation into $E$. coli. pGAD10 CDNA inserts were sequenced by automatic sequencing using the DNA sequencing facility of University of Pennsylvania.

\section{Probe preparation}

Both Cdk5 (270 bp insert BamHI/EcoRV) and p35 (250 bp insert BamHI/Notl) CDNAs were gifts of Dr. P. Zalenka (NIH). For preparation of radioactive RNA probes, DNA template was incubated with transcription solution $(1 \times$ transcription buffer, $10 \mathrm{mM}$ DTT, $0.5 \mathrm{mM}$ CPT, $0.5 \mathrm{mM}$ GTP, $50 \mathrm{mCi}^{35} \mathrm{~S}-\mathrm{UTP}$, and RNAsin, RNA polymerase) for $2 \mathrm{~h}$ at $37^{\circ} \mathrm{C}$. More polymerase was added with a further incubation for $30 \mathrm{~min}$, followed by the addition of RNase free DNase RO1 (Promega, Madison, WI, USA) and incubated for $15 \mathrm{~min}$. After the addition of total yeast RNA, solution A (10 mM DTT, $80 \mathrm{mM} \mathrm{NaHCO}_{3}$, $120 \mathrm{mM} \mathrm{Na}_{2} \mathrm{CO}_{3}$ ) was added to the digest at $60^{\circ} \mathrm{C}$, followed by the addition of solution $B(200 \mathrm{mM} \mathrm{NaOAc}, 10 \mathrm{mM}$ HOAc, $10 \mathrm{mM}$ DTT). The probes were purified on G-50 Sephadex column, ethanol precipitated and dissolved in $1 \mathrm{M}$ DTT to use at final concentration of 25 000-50 000 c.p.m./ $\mu$ l in hybridization buffer (50\% formamide, $0.3 \mathrm{M} \mathrm{NaCl}, 20 \mathrm{mM}$ Tris- $\mathrm{HCl}(\mathrm{pH} 7.4), 5 \mathrm{mM}$ EDTA, $10 \mathrm{mM}$
$\mathrm{NaH}_{2} \mathrm{PO}_{4} \mathrm{H}_{2} \mathrm{O}(\mathrm{pH} 8.0), 10 \%$ dextran sulfate, $1 \times$ Denhardt's solution, $0.5 \mathrm{mg} / \mathrm{ml}$ total yeast RNA).

\section{In situ hybridization}

The in situ hybridization was as described previously. ${ }^{30}$ Briefly, paraformaldehyde postfixed sections were incubated with proteinase $\mathrm{K}$ in PK buffer (1 M Tris, 0.5 M EDTA). After dehydration in graded ethanol, sections were hybridized with hybridization buffer and either Cdk5 or p35 probe in $10 \mathrm{mM} \mathrm{DTT.} \mathrm{Sections} \mathrm{were} \mathrm{then} \mathrm{washed} \mathrm{in} 5 \times$ SSC with $10 \mathrm{mM} \mathrm{DTT}$, in $50 \%$ formamide in $2 \times$ SSC, in $1 \times$ washing solution $(23.4 \mathrm{~g} \mathrm{NaCl}, 10 \mathrm{ml} 1 \mathrm{M}$ Tris $(\mathrm{pH} 7.5)$ with $5 \mathrm{mM}$ EDTA, in $20 \mathrm{mg} / \mathrm{ml}$ RNase $A$ in $1 \times$ washing solution, in $1 \times$ washing solution, in $2 \times$ SSC, and $0.1 \times$ SSC. Finally, the dehydrated sections were dipped in photographic NTB-2 emulsion (Kodak) and exposed for 1-2 weeks, after which they were developed (Kodak Dektol developer), fixed (Kodak), counterstained with $0.2 \%$ toluidine blue, dehydrated, and mounted with Permount.

\section{Northern blotting}

Total RNA was extracted from mouse embryos using ice-cold lysis buffer (4 M guanidinium isothiocyanate, $25 \mathrm{mM}$ sodium citrate $\mathrm{pH} 7.0$, $0.5 \%$ Sarkosyl, and $0.1 \mathrm{M} \beta$-mercaptoethanol), with the addition of $2 \mathrm{M}$ sodium acetate $(\mathrm{pH} \mathrm{4.0)}$ and phenol as well as chloroform: isoamylalcohol (49:1), in succession. Upon precipitation with isopropanolol, the RNA pellet was resuspended in lysis buffer, and precipitated again in $75 \%$ ethanol and recovered by centrifugation. After dissolving RNA in sterile $\mathrm{dH}_{2} \mathrm{O}$, we determined the concentration of RNA by measuring the absorbance at $260 \mathrm{~nm}$ and the $A_{260}: A_{280}$ ratio. Collected total RNAs were run on a $1 \%$ agarose gel and the separated bands were transferred to a nitrocellulose membrane. RNAs immobilized on the nitrocellulose were hybridized with a solution containing ${ }^{32} \mathrm{P}$-labeled RNA probe. The nonhybridized radioactive RNA probe was washed, and the hybridization was analyzed by autoradiography.

\section{Cos-7 cell culture and treatment}

Cos-7 cells were obtained from the American Type Culture Collection (ATCC) and maintained in DMEM (GIBCO BRL Inc.) supplemented with $10 \%$ fetal calf serum, $50 \mathrm{U} / \mathrm{ml}$ penicillin and $100 \mu \mathrm{g} / \mathrm{ml}$ streptomycin. The cultures were maintained in a humidified atmosphere in $95 \%$ air and $5 \% \mathrm{CO}_{2}$ at $37^{\circ} \mathrm{C}$. The cells were cultured to $80 \%$ coverage, treated with $\mathrm{CHX}(100 \mu \mathrm{g} / \mathrm{ml}) 24 \mathrm{~h}$. Incorporation of ${ }^{35} \mathrm{~S}$ methionine was as above. Cell death was assessed as described by us before in Karasavvas et al. ${ }^{41}$

\section{Acknowledgements}

This research was conducted with the support of the National Institutes of Health-National Institute on Aging, Professional Staff Congress of the City University of New York, and the Queens College Alumni Association.

\section{References}

1. Lew J, Winkfein RJ, Paudel HK and Wang JH (1992) Purification and characterization of a novel proline-directed protein kinase from bovine brain. J. Biol. Chem. 267: 25922-25926

2. Ino H, Ishizuka T, Chiba T and Tatibana M (1994) Expression of Cdk5 (PSSALRE kinase), a neural cdc2-related protein kinase, in the mature and developing mouse central and peripheral nervous systems. Brain Res. 661: 196-206 
3. Meyerson M, Enders GH, Wu CL, Su LK, Gorka C, Nelson C, Harlow E and Tsai $\mathrm{LH}$ (1992) A family of human cdc2-related protein kinases. EMBO J. 11:29092917

4. Lazaro JB, Kitzmann M, Poul MA, Vandromme M and Lamb NJC (1997) Cyclin dependent kinase $5, \mathrm{cdk} 5$, is a positive regulator of myogenesis in mouse $\mathrm{C} 2$ cells. J. Cell Sci. 110: 1251-1260

5. Tsai LH, Delalle I, Caviness VS, Chae T and Harlow E (1994) p35 is a neuralspecific regulatory subunit of cyclin-dependent kinase 5. Nature 371: 419-423

6. Zhang Q, Ahuja HS, Zakeri Z and Wolgemuth DJ (1997) Cyclin-dependent kinase 5 is associated with apoptotic cell death during developmental and tissue remodeling. Dev. Biol. 183: 222-233

7. Shirvan A, Ziv I, Agarwal-Mawal R, Machlyn T, Barzilai A and Melamed E (1998) Expression of cell cycle-related genes during neuronal apoptosis: is there a distinct pattern? Neurochem. Res. 23: 767-777

8. Henchcliffe $C$ and Burke RE (1997) Increased expression of cyclin-dependent kinase 5 in induced apoptotic neuron death in rat substantia nigra. Neurosci. Lett. 230: $41-44$

9. Patrick GN, Zukerberg L, Nikolic M, Delamonts S, Dikkes P and Tsai LH (1999) Conversion of p35 to p25 deregulates Cdk5 activity and promotes neurodegeneration. Nature 395: 194-198

10. Ahuja HS, James W and Zakeri Z (1997) Rescue of the limb deformity in Hammertoe mutant mice by retinoic acid-induced cell death. Dev. Dynamics 208: $1-16$

11. Lee M, Kwon KT, Li M, Peng J, Friedlander RM and Tsai LH (2000) Neurotoxicity induces cleavage of p35 to p25 by calpain. Nature 405: 360-364

12. Ishiguro K, Kobayashi S, Omori A, Takamatsu M, Yonekura S, Anzai K, ImahoriK and Uchida T (1994) Identification of the $23 \mathrm{kDa}$ subunit of tau protein kinase ll as a putative activator of Cdk5 in bovine brain. FEBS Lett. 342: 203-208

13. Uchida T, Ishiguro K, Ohnuma J, Takamatsu M, Yonekura S and Imahori K(1994) Precursor of Cdk5 activator, the $23 \mathrm{kDa}$ subunit of tau protein kinase II: its sequence and developmental change in brain. FEBS Lett. 355: 35-40

14. Tang D, Young J, Li KY, Matsushita M, Tomizawa K, Matsul H, Hatase $\mathrm{O}$ and Wang JH (1995) An isoform of neuronal cyclin-dependent kinase 5 (Cdk5) activator. J. Biol. Chem. 270: 26897-26903

15. Shung R, Zhang L, Fletcher A, Groblewski GE, PevsnerJ and StuenkelEL (1998) Regulation of Munc-18/syntaxin $1 \mathrm{~A}$ interaction by cyclin-dependent kinase 5 in nerve endings. J. Biol. Chem. 273: 4957-4966

16. Fletcher Al, Shuang R, Giovannucci DR, Zhang L and Bittner MA (1999) Regulation of exocytosis by cyclin-dependent kinase 5 via phosphorylation of Munc18. J. Biol. Chem. 274: 4027-4035

17. Tomizawa K, Matsui H, Matsushita M, LewJ, Tokuda M, Itano T, Konishi R, Wang $\mathrm{JH}$ and Hatase O (1996) Localization and developmental changes in the neuronspecific cyclin-dependent kinase 5 activator (p35nck5a) in the rat brain. Neurosci. 74: 519-529

18. Chae T, Kwon YT, Bronson R, Dikes P, Li E and Tsai LH (1997) Mice lacking p35, a neuronal specific activator of Cdk5, display cortical lamination defects, seizures, and adult lethality. Neuron 18: 29-42

19. Lew J, Huang QQ, Winkfein RJ, Aebersold R, Hunt T and Wang JH (1994) A brain-specific activator of cyclin-dependent kinase 5. Nature 371: 423-426

20. Kusakawa GI, Saito T, Onuki R, Ishiguro K, Kishomoto T and Hisanaga S (2000) Calpain-dependent proteolytic cleavage of the p35 cyclin-dependent kinase 5 activator to p25. J. Biol. Chem. 275: 17166-17172

21. Sobue K, Agarwal-Mawal A, Li W, Miura Y and Paudel HK (2000) Interaction of neuronal Cdc2-like protein kinase with microtubule-associated protein Tau. J. Biol. Chem. 275: 16673-16680
22. Schweichel JU and Noack W (1971) Morphology and significance of physiological cell necrosis during the development of the forelimb in rat fetus. Verh. Anat. Ges. 66: 287-295

23. Peiffer RL, McCullen R, Alles AJ and Sulik KK (1991) Relationship of cell death to cyclophosphamide-induced ocular malformations. Teratog. Carcinog. Mutagen. 11: $203-212$

24. Whitaker SJ (1992) DNA damaged by drugs and radiation: what is important and how is it measured? Eur. J. Cancer 28: 273-276

25. ZakeriZF and Ahuja HS (1994) Apoptotic cell death in the limb and its relationship to pattern formation. Biochem. Cell Biol. 72: 603-613

26. Moallem SA and Hales BF (1995) Induction of apoptosis and cathepsin D in limbs exposed in vitro to an activated analog of cyclophosphamide. Teratology 52: 3 14

27. Normura M, Suzuki M, Suzuki Y, Ikeda H, Tamura J, Koike M, Jie T and Itoh G (1996) Cyclophosphamide-induced apoptosis induces phocomelia in the mouse. Arch. Toxicol. 70: 672-677

28. Cai XH, Tomizawa K, Tang D, Lu YF, Moriwaki A, Tokuda M, Nagahata S, Hatase $O$ and Matsui $H$ (1997) Changes in the expression of novel Cdk5 activator messenger RNA (p39nck5ai mRNA) during rat brain development. Neurosci. Res. 28: 355-360

29. Mirkes PE (1985) Cyclophosphamide teratogenesis: A review. Teratology 32: $259-266$

30. Ahuja HS, Zhu Y and Zakeri Z (1997) Association of cyclin-dependent kinase 5 and its activator p35 with apoptotic cell death. Dev. Genet. 21: 258-267

31. Oshima T, Ward JM, Huh CG, Longenecker G, Veerann A, Pant HC, Brady RO, Martin LI and Kulkarni AB (1996) Targeted disruption of the cyclin-dependent kinase 5 gene results in abnormal corticogenesis, neuronal pathology and perinatal death. Proc. Natl. Acad. Sci. USA 93: 11173-11178

32. Kwon YT, Gupta A, Zhou Y, Nikolic M and Tsai LH (2000) Regulation of Ncadherin-mediated adhesion by the p35/cdk5 kinase. Curr. Biol. 10: 363-372

33. Lee MK and Cleveland DW (1996) Neuronal intermediate filaments. Annu. Rev. Neurosci. 19: $187-217$

34. Mandelkow EM and Mandelkow E (1998) Tau in Alzheimer's disease. Trends Cell Biol. 8: $425-427$

35. Brancolini C, Benedetti M and Schneider C (1995) Microfilament reorganization during apoptosis: the role of Gas2, a possible substrate for ICE-like Proteases. EMBO J. 14: 5179-5190

36. Jochová J, Zakeri Z and Lockshin RA (1997) Early collapse of the cytoskeleton in the programmed cell death of the Drosophila salivary gland. Cell Death Diff. 5: $140-149$

37. Francis BM, Rogers JM, Sulik KK, Alles AJ, Elstein KH, Zuker RM, Massaro EJ, Rosen MB and Chernoff N (1990) Cyclophosphamide teratogenesis: evidence for compensatory response to induced cellular toxicity. Teratology 42: 473-482

38. Zakeri Z, Quaglino D and Ahuja HS (1994) Apoptotic cell death in the mouse limb and its suppression in the hammertoe mutant. Dev. Biol. 165: 294-297

39. Bradford (1970) Metabolic response of synaptosomes to electrical stimulation: release of amino acids. Brain Res. 19: $239-247$

40. Laemmli EK (1970) Cleavage of structural proteins during the assembly of the head of bacteriophage T4. Nature 227: 680-685

41. Karasavvas N, Erukulla RK, Bittman R, Lockshin Rand ZakeriZ(1996) Octanoyl sphingosine stereoisomers and n-octyl sphingosine induce apoptosis with variable potency in U937 cells. The ceramide carbonyl group is not required for apoptosis. Eur. J. Biochem. 236: 729-737 